\title{
Loadings for Insurance Premiums
}

\author{
by Sidney Benjamin*
}

\section{Introduction}

The premium to be charged by an insurer i.e. "office premium" can be expressed as office premium $=$ pure risk premium + loadings.

The subject of this paper is the loadings. They can be expressed as loading for,

(i) commission

(ii) expenses

(iii) $\operatorname{tax}$

(iv) variability of risk

and (v) profit margin

Item (iv) can be expressed in terms of the standard deviation of the risk or of the variance of the risk.

Before returning to the above analysis we shall approach the subject from a different point of view using some simplified examples.

\section{Example 1:}

The contract

The insurer will pay $£ 1$ for every Head of 100 tosses of a coin.

\section{Statistical analysis}

Number of tosses

Average number of Heads

High Number of Heads
100

50

65

(NOTE: If an underwriter tosses 100 coins a large number of times he will find that 65 or more Heads turn up very infrequently.)

\footnotetext{
* Partner, Bacon and Woodrow, London.

Visiting Professor, The City University, London.
} 


\section{Financial analysis}

Immediately after he receive the premium the insurer should be able to withstand a loss of $\mathfrak{6 6 5}$, if necessary, i.e. he should show a fund of $\mathfrak{£} 65$.

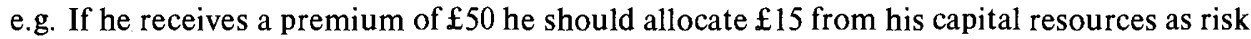
capital. (This can remain outside the premium trust fund but is allocated working capital until the experience on this risk allows some or all of it to be released.)

He may not receive a premium of $£ 50$ in the market. Nevertheless, the balance of $\mathfrak{1 6 5}$ should be allocated from working capital.

Financial statement

\begin{tabular}{lc}
$\begin{array}{l}\text { Opening Fund } \\
\quad \text { (premium }+ \text { risk capital) }\end{array}$ & 65 \\
Expected Claims & 50 \\
\hline Expected Surplus & 15
\end{tabular}

\section{Example 2}

The contract

Suppose the market allows the insurer to obtain a premium of $\mathfrak{1 5 5}$. The opening financial position is

\begin{tabular}{ll} 
Premium & 55 \\
Risk Capital & 10 \\
\hline Opening Fund $=$ & $65=$ Reserve
\end{tabular}

It the insurer experts (on average) to have to pay claims of $\mathfrak{f} 50$ on 50 Heads then the total financial position can be expressed as:

Financial statement

$\begin{array}{lrr}\text { Premium } & 55 & \\ \text { Risk Capital } & \underline{10} & \text { IN } \\ \text { Total Fund } & \mathfrak{f 6 5}\end{array}$

$$
\begin{array}{rr}
\text { Claim } & 50 \\
\text { Average OUT Surplus } & \underline{15} \\
\text { Total } & \mathfrak{£ 6 5}
\end{array}
$$

Separation of cash flows

Let us split the expected financial picture into two parts:

(a) the policy holder

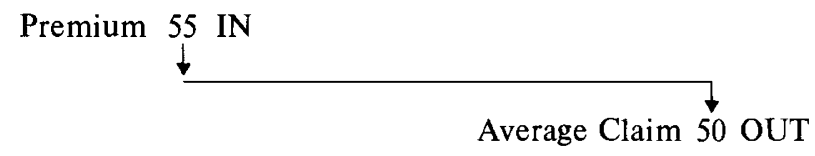


(b) the insurer

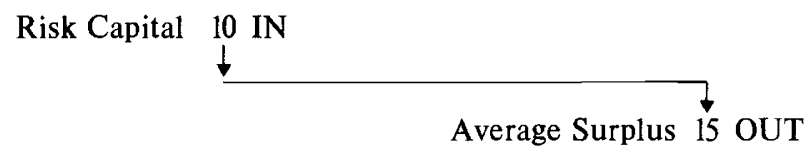

Financial analysis for the insurer

Capital required $=£ 10$

(Average) return on capital $\frac{15-10}{10}=50 \%=$ YIELD

\section{Example 3}

\section{Analysis of experience}

Now suppose that in fact 58 Heads turn up, causing claims of $£ 58$. The actual financial result becomes

(a) the policyholder

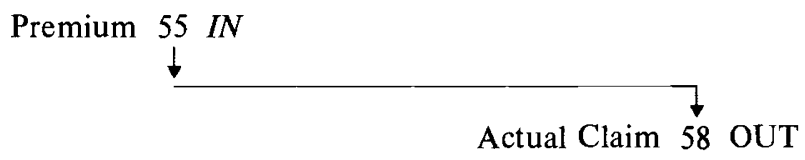

(b) the insurer

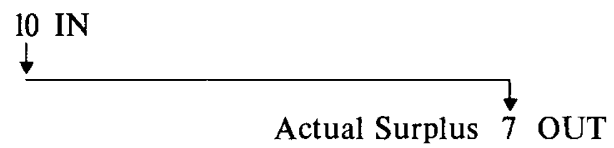

Financial analysis of experience for the insurer

Capital required $=£ 10$ as before

(Actual) return on capital $\frac{7-10}{10}=-30 \%$

\section{Comment 1}

The opening fund (or reserve) of $£ 65$ is determined by taking a cautious view of the future risk. The premium will almost certainly not cover the whole $£ 65$.

\section{Comment 2}

The premium is the money which can be obtained in the market and in principle has nothing to do with the $\mathfrak{f} 65$ opening reserve.

\section{Comment 3}

The risk capital required is the balance required which, together with the premium, will provide the required opening reserve. The actuarial term for this risk capital is "the new business strain". 


\section{Comment 4}

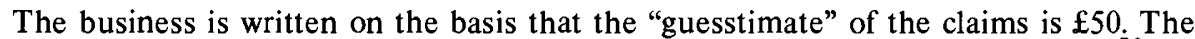
underwriter might say to himself that a premium of $£ 55$ will give a likely loss-ratio of $\frac{50}{55}$ i.e. $91 \%$ but that amounts to the same thing.

\section{Comment 5}

To carry out a financial analysis we separate the total transaction into two parts, and identify two cash flows:

(a) The policyholder's "cash flow" of premiums 'in' and claims 'out'. This is familiar. And

(b) The insurer's "cash flow" of "new business strain" in and "surplus" out. This is not familiar.

\section{Comment 6}

Surplus is not the same as profit. Example 3, where the surplus $=\mathfrak{f 7}$, makes this clear.

As we shall see later, "surplus" is the amount which can be released from the fund whilst leaving sufficient in the fund to reserve cautiously for the remainder of the risk. In this example the risk has run off and the whole of the fund can be released as surplus.

Surplus which is released is then available as risk capital for further new business.

\section{Comment 7}

The profit in Example 1 is

surplus - new business strain

e.g. $15-10=5$

In more complicated examples it is better expressed as a return on capital e.g. $\quad \frac{15-10}{10}=50 \%$

\section{Comment 8}

Once the experience is known then the actual return on capital can be calculated in the same manner, and of course the actual profitability is unlikely to be exactly as "guesstimated" when the business was written.

\section{Example 4}

We now make our example slightly more realistic by introducing a claims 'tail'.

\section{The contract}

Pay $\mathfrak{f l}$ for every Head in 300 tosses of a coin. The coins are all tossed in Year 1 . The results of the first hundred are reported in Year 1, the result of the next hundred in Year 2 and the results of the last hundred in Year 3. 
The analysis

We shall look at

the capital required, the premium to be charged, the return on capital,

and we shall draw up accounts at the end of each year.

\section{Statistical analysis}

We use the following table which can be calculated by statistical theory or can be found by tossing lots of coins for a long time.

Coin tossing: Basic table

$\begin{array}{ccc}\begin{array}{c}\text { No. of } \\ \text { Tosses }\end{array} & \begin{array}{c}\text { Average } \\ \text { no. of } \\ \text { Heads }\end{array} & \begin{array}{c}\text { High } \\ \text { no. of } \\ \text { Heads }\end{array} \\ 100 & 50 & 65 \\ 200 & 100 & 122 \\ 300 & 150 & 176\end{array}$

Financial analysis

$\begin{array}{lrrr} & 1 \text { st } & \text { 2nd } & \text { 3rd } \\ & 100 & 100 & 100 \\ \text { (i) Opening Fund } & * 176 & 122 & 65 \\ \text { (ii) Expected Claims } & 50 & -50 & 50 \\ \text { (iii) Closing Fund } & 126 & 72 & 15 \\ \text { (iv) Reserve for } & 122 & 65 & - \\ \text { o/s tosses } & 4 & 7 & 15 \\ \text { (v) Surplus (distributed) } & & & -\end{array}$

*(vi) Capital + Premium e.g. $16+160$

\section{Notes}

Line (i) Opening Fund: At the beginning of each year we need to hold a fund (reserve) large enough to meet future claims estimated on a cautious basic. The figures are taken from the statistical table - which we can think of as the result of statistical analysis of past experience.

Line (ii) "Guesstimate" of expected claims.

Line (iii) Merely line (i)-line (ii).

Line (iv) Reserve for $\mathrm{O} / \mathrm{S}$ tosses. These are the amounts required in line (i). 
Line (v) The surplus which can be released from the fund in order to leave sufficient reserve $\mathrm{c} / \mathrm{f}$ is (iii)-(iv).

Line (vi) Noted that the required opening fund is made up from premium and risk capital. The risk capital (also known as the "new business strain") is a balancing item.

Separation of cash flows

We can, as before, identify two separate "cash flows"

(a) the policyholder's and

(b) the insurer's (or "shareholder's")

as follows:

Policyholders

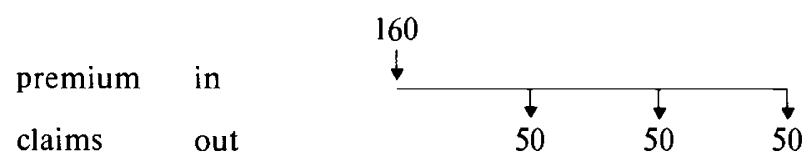

Shareholders

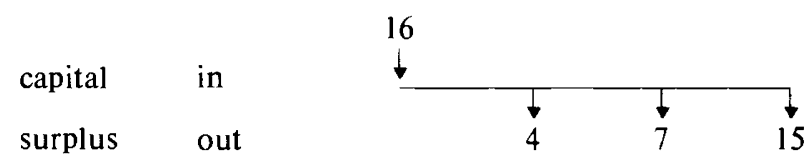

Financial analysis for the insurers

We can also use discounted cash flow technique on the insurer's cash flow. Assuming that the market premium is $£ 160$ :

THEN the risk capital required is $\mathfrak{f 1 6}$ and the return on capital is $23 \%$ p.a. The yield of $23 \%$ p.a. can be checked as follows:

Treating the risk capital as a loan to the "insurance fund" (or "premium trust fund") which is repaid with interest by the three surplus amounts released:

$\begin{array}{lr}\text { "loan } & 16.00 \\ \text { add interest at 23\% } & 3.68 \\ & 19.68 \\ \text { repay first "surplus" } & 4.00 \\ \text { balance of loan } & 15.68 \\ \text { add interest at 23\% } & 3.61 \\ & 19.29 \\ \text { repay second "surplus" } & 7.00 \\ \text { balance of loan } & 12.29 \\ \text { add interest at 23\% } & 2.83 \\ & 15.12 \\ \text { repay third "surplus" } & 15.00 \\ \text { balance of loan } & \text { nil (.12 rounding) }\end{array}$


Note 1

The amount of surplus 4,7 and 15 released at the ends of the years become available as risk capital which is free to support more new business (strain).

Note 2

The yield of $23 \%$ p.a. on risk capital is the "risk rate of return" on the risk capital. It has nothing to do with interest earned on investments.

\section{Example 5}

We now introduce the fact that both risk capital and premium monies are invested. for simplicity we assume they earn $10 \%$ in each year. We also assume that the market premium is $£ 140$.

Note, because we continue to use undiscontinued reserves, that the reserves required to start each year are the same as before. However, the surpluses emerging are larger because of the interest earnings.

Because the required opening reserve is still $£ 176$ the new business strain - or risk capital to be allocated - is the balance of $£ 36$.

Financial statement

PREMIUM

1st Year

2nd Year

3rd Year

CAPITAL

OPENING FUND

140

10\% INTEREST

36

$176 \quad 122$

65

$\frac{17}{193}$

$\frac{12}{134}$

$\frac{6}{71}$

CLAIMS

CLOSING FUND

$\frac{50}{143}$

$\frac{50}{84}$

$\frac{50}{21}$

RESERVE FOR o/s

$\frac{122}{21}$

$\frac{65}{19}$

SURPLUS

Separation of cash flows

Again we can separate the cash flow into two parts:

Policyholders

premium in

claims out

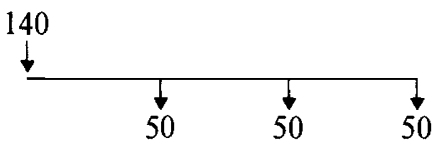

Shareholders

$\begin{array}{ll}\text { capital } & \text { in } \\ \text { surplus } & \text { out }\end{array}$

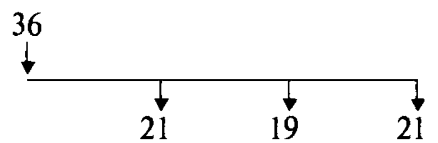

Shareholders' Yield $=32 \%$ p.a. 
We again show that the return of $32 \%$ p.a. is correct by treating the new business strain of $\mathfrak{f} 36$ as a loan to the insurance fund which is repaid with interest by the surpluses of $\mathfrak{1} 21, \mathfrak{f} 19$ and

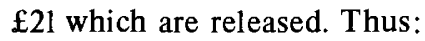

$\begin{array}{lr}\text { "loan } & 36.00 \\ \text { add interest at 32\% } & \frac{11.52}{47.52} \\ \text { repay first "surplus" } & \frac{21.00}{26.52} \\ \text { balance of loan } & \frac{8.49}{35.01} \\ \text { add interest at 32\% } & 19.00 \\ & 16.01 \\ \text { repay second "surplus" } & 5.12 \\ \text { balance of loan } & 21.13 \\ \text { add interest at 32\% } & 21.00 \\ \text { repay third "surplus" } & \text { nil (.13 rounding) } \\ \text { balance of loan } & \end{array}$

\section{Example 6}

We now assume that the premium is received in three parts: $40 \%$ at the beginning of the first year, $35 \%$ at the beginning of the second year and the remaining $25 \%$ at the beginning of the third year.

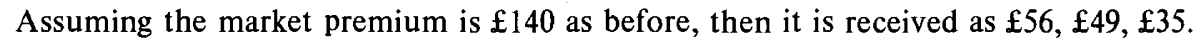

\section{Definition of a reserve}

We now need to widen our definition of a reserve and move closer to an actuarial definition of a reserve at any point of time:

The reserve $=$ that amount which together with future premium income will be sufficient to pay future claims, all estimated on a cautious basis,

Let us consider first the reserves required at various times.

\section{Opening reserve}

(immediately before first year premium is received) i.e. "new business strain" or "capital required".

The future claims, estimated on a cautious basis $=176$

The future premiums income $=$ (estimated on a

cautious basis)

$$
\begin{aligned}
& =\frac{140}{36} \\
& =1
\end{aligned}
$$

Reserve $=($ balance $)$

\section{Reserve at end of first year}

(after payment of claims, before second year premium, i.e. as at a balance sheet date) 
$\begin{array}{ll}\text { Future claims estimated on a cautious basis } & =122 \\ \text { Future premium income }=49+35 & =\frac{84}{38} \\ \text { Balance }=\text { reserve }(\mathrm{c} / \mathrm{f} \text { to second year }) & =3\end{array}$

Reserve at end of second year

$\begin{array}{ll}\text { Future claims estimated on a cautious basis } & =65 \\ \text { Future premium income } & =\frac{35}{30} \\ \text { Balance }=\text { reserve (c/f to third year) } & =30\end{array}$

Financial statement

The accounts now look like this:

Reserve b/f

1st Year

2nd Year

3rd Year

Premium

56

38

30

Capital

Opening Fund

$\frac{36}{92}$

49

35

$10 \%$ interest

$\frac{9}{101}$

$\frac{-}{87}$

$-$

Claims paid

Closing Fund

$\frac{50}{51}$

$\frac{9}{96}$

$\frac{6}{71}$

Reserve c/f

Surplus

$\frac{38}{13}$

$\frac{50}{46}$

$\frac{50}{21}$

Note (1)

The reserves which appear were calculated first.

Note (2)

Because the reserves were on a cautious basis no further capital was required (to be "transferred in") after supporting the opening new business strain.

Note (3)

The return on the risk capital (new business strain) of 36 - is $17 \%$ p.a.

Thus, as earlier

$\begin{array}{lr}\text { "loan" } & 36.00 \\ \text { add interest at 17\% } & 6.12 \\ & 42.12 \\ \text { repay first "surplus" } & \frac{13.00}{29.12} \\ \text { balance of loan } & \frac{4.95}{34.07} \\ \text { add interest } & 16.00 \\ \text { repay second "surplus" } & 18.07 \\ \text { balance of loan } & \end{array}$

(continues) 
(continues)
add interest at $17 \%$
3.07
21.14
repay third "surplus"
21.00
balance of loan
nil (.14 rounding)

Note (4)

The rate of return on the capital is less than before because the premiums came in later and earned less interest (at $10 \%$ p.a.) from investment.

\section{Remark 1}

We have assumed that the expected likely average experience in our example is $£ 50$ claims in each of three years. In practice the figures we use, however expressed, will be based on a look at the past and an estimate of the future and the term 'anticipated actual experience' is a useful description. It is the reasonably likely future experience on which we write the business.

The reserving basis on the other hand, including the risk capital, is on a cautious view of the future. In principle, it ought to be sufficiently cautious to make any requirement for future capital injections to be very unlikely. (A reserving basis which is intended to achieve that aim is called a "coherent" basis).

\section{Remark 2}

Given our estimates, however rough, of

(i) the anticipated actual experience, and

(ii) a cautious reserving basis,

we can assess a market premium on the basis of

(a) the amount of the new business strain i.e. risk capital to be allocated to the portfolio (outside the premium trust fund) and

(b) the likely rate of return (or "risk yield") on that capital.

\section{General remarks}

\section{Remark 3}

Loadings for expenses and commission, allowance for tax, adjustments for discounted reserves and a mismatching reserve for mismatching between assets and liabilities, can be inserted into the figures at the appropriate points of time and do not affect the principles of the calculation. 


\section{Valuation basis for loss ratios}

We now turn from coin tossing and show how an acceptable cautious valuation basis can be obtained in practice from the history of ultimate loss ratios in a particular category of business.

The table shows for years of account 1961-1975 in column (1) the ultimate loss ratios in column (2).

To prepare for the method of analysis the 15 ultimate loss ratios have been sorted into ascending order in column (3).

Column (4) shows the position of the 15 items marked off in intervals of $1 / 16$. It is argued that there is a chance of $1 / 16$ of obtaining an ultimate loss ratio less than $65 \%$, a chance of $2 / 16$ of an ultimate loss ratio less than $68 \%$ etc. The denominator 16 is used instead of 15 to allow for a chance of obtaining an ultimate loss ratio greater than the highest, $107 \%$.

\section{ULT L.R.}

YR. of $\mathrm{A} / \mathrm{C}$

1961

62

63

64

65

66

67

68

69

70

71

72

73

74

75
ULT L.R.

\section{$74 \%$}

76

82

87

96

88

86

80

81

71

68

65

69

107

78

\section{In}

Ascending

Order

$65 \%$
68
69
71
74
76
78
80
81
82
86
87
88
96
107

\section{Position}

$1 / 16=6 \%$

$2 / 16=13 \%$

$3 / 16=19 \%$

$4 / 16=25 \%$

$5 / 16=31 \%$

$6 / 16=38 \%$

$7 / 16=44 \%$

$8 / 16=50 \%$

$9 / 16=56 \%$

$10 / 16=63 \%$

$11 / 16=69 \%$

$12 / 16=75 \%$

$13 / 16=81 \%$

$14 / 16=88 \%$

$15 / 16=94 \%$

The following is a special graph of these values. The horizontal axis marked off according to the Normal distribution and the vertical axis is marked off in logarithmic distances. Printed graph paper known as "lognormal" graph paper is commercially available.

(In the case of coin-tossing the number of heads is the result of adding together a lot of random results i.e. heads or tails. In the case of financial statistics such as size of claim, or loss ratio, the final figure is the result of a lot of percentage changes i.e. the result of a lot of multiplications; this makes a logarithmic scale useful.) 


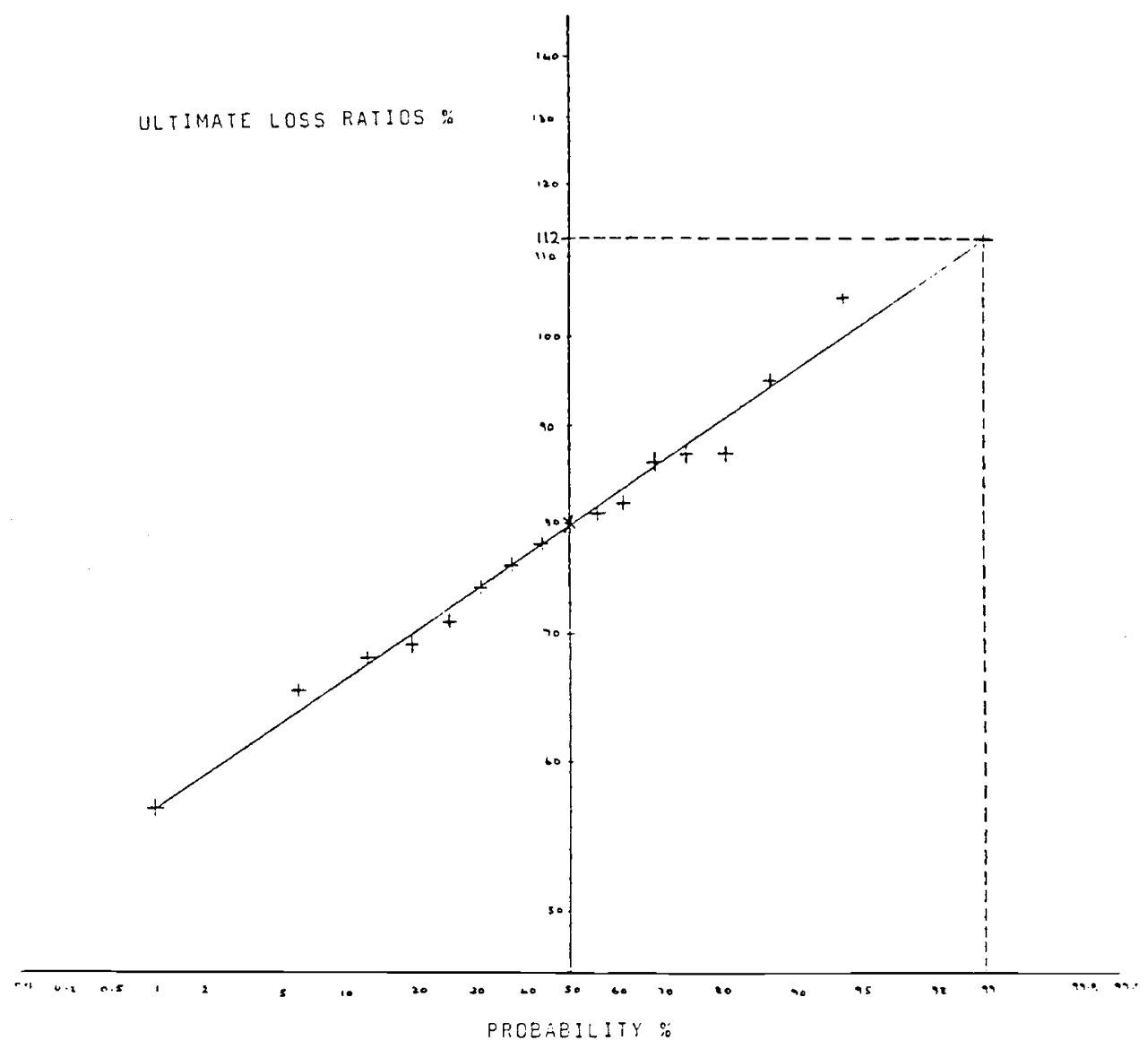

From the graph we can see that the points lie reasonably on a straight line. We can extrapolate the line and read off the graph the Ultimate Loss Ratio which is likely to be exceeded in only 1 in 100 times; it is an Ultimate Loss Ratio of $112 \%$. This is now our cautious estimate of an opening reserve.

Incidentally, we can also see from the graph that there is a " $50: 50$ " chance that an Ultimate Loss Ratio of $80 \%$ will be exceeded. (The average of the 15 numbers is $80.5 \%$ ).

Years of development

Elsewhere we have shown how the Paid Loss Ratio at the end of Year of Development 1 could be used to form a line, with a "path" around the line, to estimate the Ultimate Loss Ratio. 
The history of 9 years of account are plotted as shown. The loss ratio at the end of the first year of development is plotted along the horizontal axis and the corresponding ultimate loss ratio is plotted along the vertical axis.

The line of the best fit is drawn through the points and a symmetrical path drawn about the line just enclosing all the points. The width of the path is thus a measure of the variability. (This is straightforward. The use of the standard deviation to set a confidence paths is better.)

The formula gives the equation(s) of the three lines.

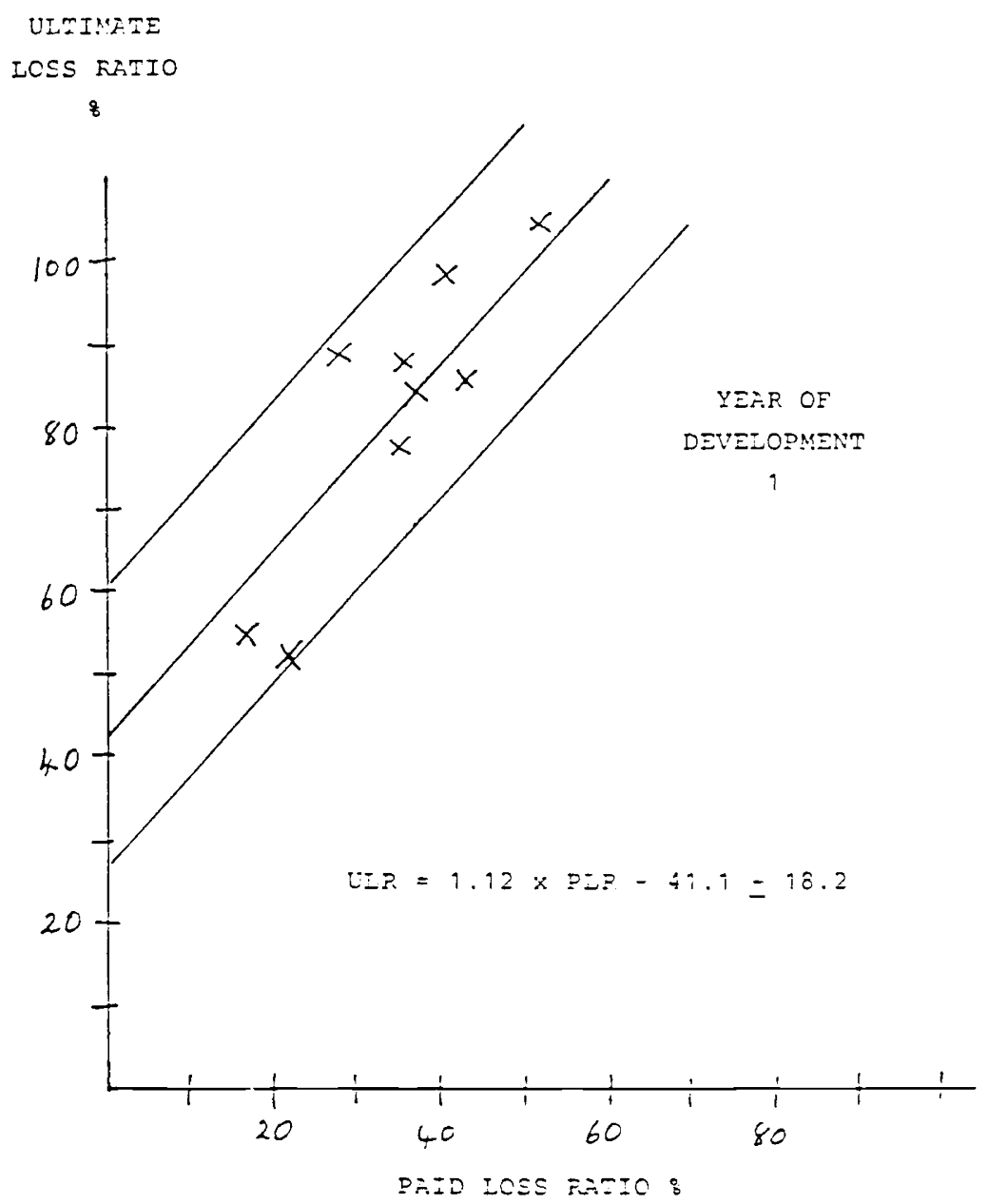

The same Audit Category (Aviation Short Tail) graphs at Years of Development 1 (i.e. repeated), 2, 3 and 4 are as follows: 


\section{AVIATION SHORT-TALL}

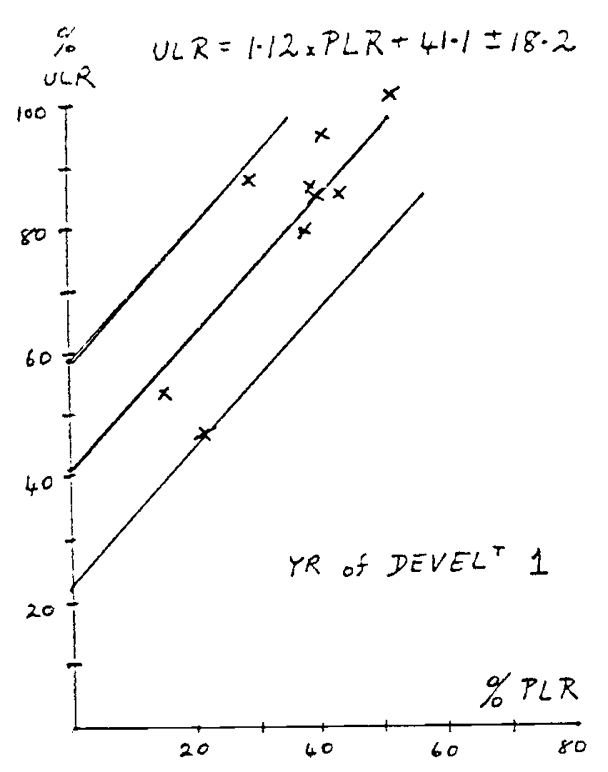

$\overbrace{0} \quad U L R=1 \cdot 16 \times P I R-4 \cdot 2=9 \cdot 8$
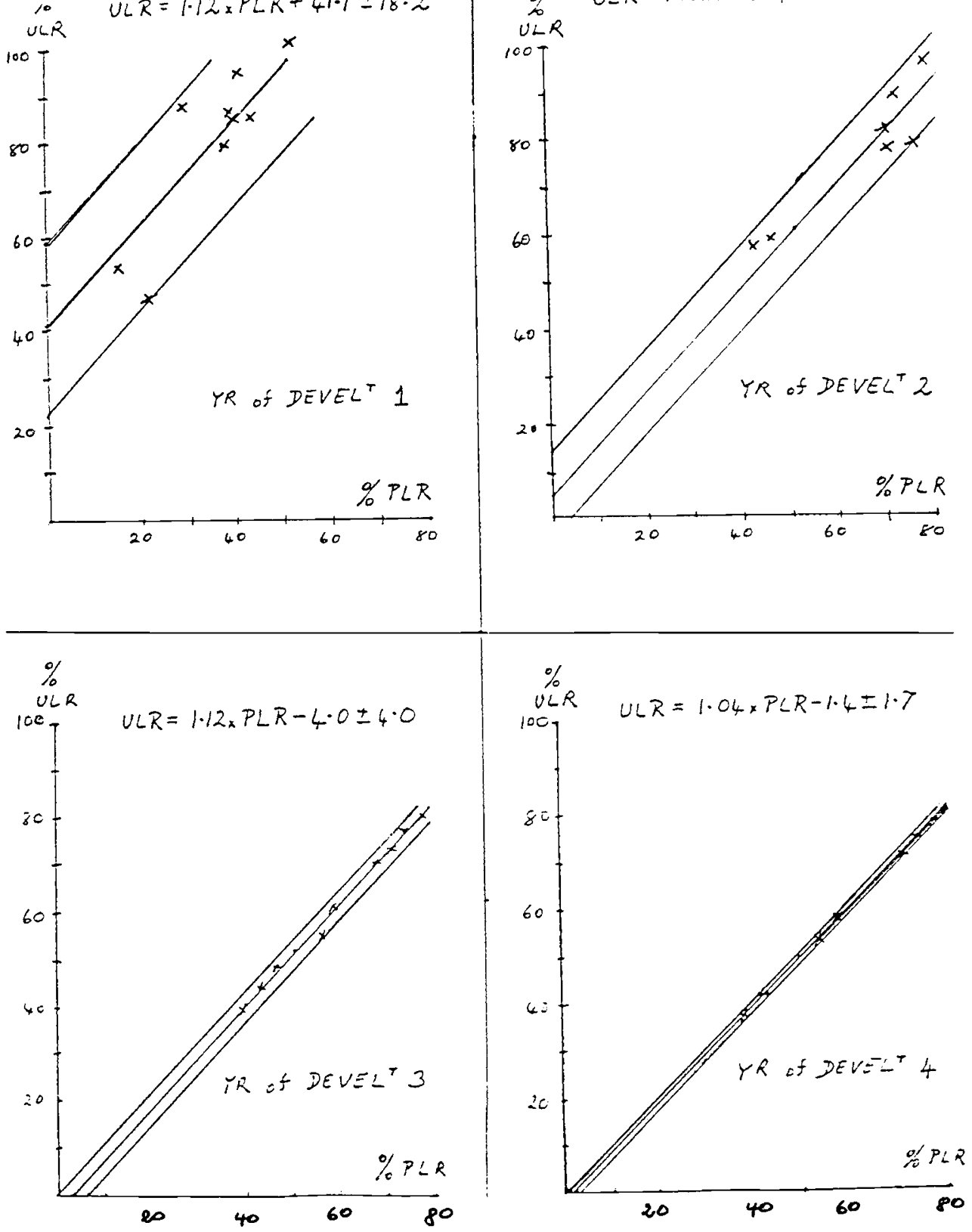
We can use the upper adge of each of these paths to obtain a cautious estimate of the Ultimate Loss Ratio based on the actual Paid Loss Ratio at ach Year of Development. follows:

The equations of the upper edges of the "paths" for Years of Development 1 ti 4 are as

YEAR OF DEVELOPMENT

0
1
2
3
4
5

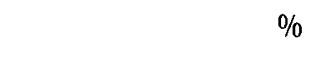

ULR

$\mathrm{ULR}=1.12 \times$ PLR

$\mathrm{ULR}=1.16 \times \mathrm{PLR}$

$\mathrm{ULR}=1.12 \times \mathrm{PLR}$

$\mathrm{ULR}=1.04 \times \mathrm{PLR}$

$\mathrm{ULR}=$

PLR

\section{MARGIN}

$$
\begin{aligned}
& 80.5+31.5=112 \\
& 41.2+18.2 \\
& 4.2+9.8 \\
& 4.0+4.0 \\
& 1.4+1.7
\end{aligned}
$$

At Year of Development 5 this particular Audit Category is run off so the Paid Loss Ratio is the Ultimate Loss Ratio.

The opening cautious estimate of the Ultimate Loss Ratio made from the earlier, separate, "log-normal" graph, of $112 \%$ is shown as Year of Development 0 because it is estimated from past experience before any business is written. Is is shown as split between the average Ultimate Loss ratio of $80.5 \%$ and the consequential "margin" of $31.5 \%$ making the required total of $112 \%$.

Following an experience

We follow through an actual experience. The basic data are as follows:

CUMULATIVE

YEAR OF DEVELOPMENT

(1)

(0)

1

2

3

4

5

\section{PREMIUMS \\ RECEIVED}

(2)

0

40

80

100

100

100

\section{CLAIMS PAID}

(3)

0

13.6

55.1

78.0

80.9

80.9
FORMULA

ULR

PLR\%

(4)

0

34.0

68.9

78.0

80.9

80.9
$+$

MARGIN

(5)

112.2

97.5

93.9

87.4

84.4

80.9

In respect of 100 of ultimate premium received we assume in column (2) that 40 is received in Year 1, another 40 in Year 2, and the final 20 in Year 3.

In column (3) we show actual claims paid and in column (4) $=(3) /(2)$ we show the Paid Loss Ratio to date. 
These Paid Loss Ratios can be inserted into the previous formulae to obtain cautious estimates of the Ultimate Loss Ratio. The results are in column (5) and we can see that the margin for caution narrows as time develops.

\section{Conclusion}

Given an acceptably cautious valuations basis for demonstrating an adequate standard of solvency, the insurer can test any proposed premium rate against his own "anticipated actual" experience in order to see whether there is an acceptable allowance for claims, expenses and a reasonable risk rate of return on his capital.

The paradigm which used

"office premium = risk premium + loadings"

has been superseded. 